\title{
Risk of adverse outcomes among infants of immigrant women according to birth-weight curves tailored to maternal world region of origin
}

\author{
Marcelo L. Urquia PhD MSc, Howard Berger MD, Joel G. Ray MD MSc; for the Canadian Curves Consortium*
}

Competing interests: None declared.

This article has been peer reviewed.

*Members of the Canadian Curves Consortium are listed at the end of the article.

\section{Correspondence to:}

Marcelo Urquia,

UrquiaM@smh.ca

CMAJ 2015. DOI:10.1503 /cmaj.140748

\begin{abstract}
- Abstract
Background: Infants of immigrant women in Western nations generally have lower birth weights than infants of native-born women. Whether this difference is physiologic or pathological is unclear. We determined whether the use of birth-weight curves tailored to maternal world region of origin would discriminate adverse neonatal and obstetric outcomes more accurately than a single birth-weight curve based on infants of Canadian-born women.
\end{abstract}

Methods: We performed a retrospective cohort study of in-hospital singleton live births (328 387 to immigrant women, 761260 to nonimmigrant women) in Ontario between 2002 and 2012 using population health services data linked to the national immigration database. We classified infants as small for gestational age ( $<10$ th percentile) or large for gestational age ( $\geq 90$ th percentile) using both Canadian and world region-specific birthweight curves and compared associations with adverse neonatal and obstetric outcomes.

Results: Compared with world region-specific birth-weight curves, the Canadian curve classified $20431(6.2 \%)$ additional newborns of

I n many Western nations, an increasing proportion of births are to immigrant women, many from world regions where low birth weight and infant death are more frequent. ${ }^{1-3}$ The birth-weight distribution of infants born to immigrant mothers in Canada and the United Kingdom is shifted toward lower birth-weight values than that of infants born to native-born women. ${ }^{4,5} \mathrm{Ac}$ cordingly, use of a conventional population-based birth-weight chart may not be appropriate for all immigrant groups, potentially leading to an overestimation of infants as small for gestational age (birth weight $<10$ th percentile) and an underestimation of infants as large for gestational age (birth weight $\geq 90$ th percentile). The question remains whether these differences reflect a physiologic or a pathological process. immigrant women as small for gestational age, of whom 15467 (75.7\%) were of East or South Asian descent. The odds of neonatal death were lower among small-for-gestational-age infants of immigrant women than among those of nonimmigrant women based on the Canadian birth-weight curve (adjusted odds ratio [OR] $0.83,95 \%$ confidence interval $[\mathrm{Cl}]$ 0.72-0.95), but higher when small for gestational age was defined by the world regionspecific curves (adjusted OR 1.24, 95\% Cl 1.081.42). Conversely, the odds of some adverse outcomes were lower among large-forgestational-age infants of immigrant women than among those of nonimmigrant women based on world region-specific birth-weight curves, but were similar based on the Canadian curve.

Interpretation: World region-specific birthweight curves seemed to be more appropriate than a single Canadian population-based curve for assessing the risk of adverse neonatal and obstetric outcomes among small- and large-for-gestational-age infants born to immigrant women, especially those from the East and South Asian regions.

Potentially misclassifying the physiologically small, but healthy, newborn as small for gestational age may lead to unnecessary interventions and undue parental stress. ${ }^{6}$ To date, comparisons between a single population-based standard and customized standards, including ones that are based on ethnicity, have focused on small-for-gestational-age infants, but less attention has been paid to the potential underclassification of large infants. ${ }^{7-9}$ Overlooking a fetus or infant who would be considered large for gestational age according to the birthweight distribution in his mother's country of origin, but not according to the higher cut-off of a birth-weight curve for infants of Canadianborn women, may fail to identify a higher risk of birth trauma or obstetric complications, such 
as perineal laceration, shoulder dystocia and postpartum hemorrhage. ${ }^{10-12}$

To date, there is no consensus regarding the minimal set of maternal characteristics that improves detection of adverse outcomes through the use of customized charts. ${ }^{13-17}$ So far, the single characteristic that has been shown to influence the size of newborns in this way is maternal country of birth. ${ }^{18}$

We conducted a study to determine whether use of world region-specific birth-weight curves would be more accurate than use of a single birth-weight curve based on infants of Canadian-born women in predicting adverse neonatal and obstetric outcomes known to be associated with small for gestational age and large for gestational age among infants born to immigrant women in Canada.

\section{Methods}

\section{Study design and population}

We completed a population-based retrospective cohort study of linked data obtained from the Institute for Clinical Evaluative Sciences. We included all singleton infants who were born alive at 23-41 weeks' gestation in an Ontario hospital between Apr. 1, 2002, and Mar. 31, 2012, who had a birth weight of $250 \mathrm{~g}$ or more and whose mother was 15-49 years of age at delivery. About $99 \%$ of all births in the province of Ontario occur in a hospital. We identified all births using the Discharge Abstract Database of the Canadian Institute for Health Information. These maternal-newborn records were linked to data in the Citizenship and Immigration Canada database. This database contains the landing records of new permanent residents to Canada between 1985 and 2010, and we obtained records for those whose intended destination was Ontario. ${ }^{19,20}$

\section{Birth-weight curves}

Maternal country of origin and the corresponding world region (Appendix 1, available at www.cmaj .ca/lookup/suppl/doi:10.1503/cmaj.140748/-/DC1) were determined on the basis of strict supporting documentation provided during the immigration application process and recorded in the Citizenship and Immigration Canada database. To assess infants' small- and large-for-gestational-age status, we used previously published birth-weight curves tailored to the most prevalent maternal world regions of origin of immigrants to Ontario. ${ }^{4}$ In brief, the curves were based on 766688 Ontario births at 23-41 weeks' gestation, including 280089 births to immigrant women, and created with the use of nonparametric quantile regression methods to derive birth-weight percentiles based on sex- and gestational age-specific birth-weight distributions. Curves were generated and smoothed with the use of a cubic spline with 3 degrees of freedom, with knots located at 23, 30, 39 and 40 weeks' gestation, and the Madsen and Nielsen smoothing algorithm. The location of the knots was determined by means of stepwise backward regression using all births.

The birth-weight curves were created separately for each stratum of maternal world region of origin (Europe and Western Nations; Africa and Caribbean; North Africa and Middle East; Latin America; East and Southeast Asia, and the Pacific; and South Asia), as well as a single stratum for newborns of Canadian-born women. ${ }^{21}$ Using these curves, we jointly categorized each hospital birth as small for gestational age $(<10$ th percentile) or large for gestational age ( $\geq 90$ th percentile) in 2 ways: (a) by applying the cut-off points of the single stratum for infants of Canadian-born women to all newborns, and (b) by applying the world region-specific cut-off points to newborns based on their mother's birth place.

\section{Outcome measures}

Outcome measures were obtained from the Discharge Abstracts Database. The database contains up to 25 fields for diagnoses coded according to the International Statistical Classification of Diseases and Related Health Problems, 10th Revision, Canadian Edition (ICD-10-CA) and 16 procedures coded according to the Canadian Classification of Health Interventions (CCI). To assess the consequences of potential misclassification of a newborn as small for gestational age, we assessed, a priori, several neonatal outcomes known to be associated with small for gestational age: neonatal death within 28 days after birth (main study outcome); prolonged hospital stay ( $\geq 7 \mathrm{~d}$ ), equivalent to about the 95th percentile for length of stay; admission to a neonatal intensive care unit during the index hospital stay; mechanical ventilation; and intrauterine hypoxia or birth asphyxia. To assess the consequences of potential misclassification related to large for gestational age, we examined some of the aforementioned neonatal outcomes, as well as specific obstetric outcomes associated with large for gestational age, such as third- or fourth-degree perineal laceration, obstructed labour due to shoulder dystocia and postpartum hemorrhage. ${ }^{1-3,15}$ Diagnostic and procedural codes for each of the outcomes are listed in Appendix 2 (available at www.cmaj.ca/lookup /suppl/doi:10.1503/cmaj.140748/-/DC1).

\section{Statistical analysis}

We performed logistic regression analysis to generate adjusted odds ratios (ORs) and 95\% confidence intervals (CIs), comparing the odds of each 
adverse neonatal or obstetric outcome in association with an infant being classified as small for gestational age or large for gestational age on the Canadian curve versus the world region-specific curves. We used the nonimmigrant population as the reference group. We adjusted the ORs for covariates selected in advance: parity, maternal age at delivery, neighbourhood income quintile ${ }^{22}$ and year of delivery. We also stratified neonatal mortality by preterm birth status. We further examined the impact of the 2 size classifications on the disparities in neonatal mortality associated with maternal country of birth, overall and within small-for-gestational-age strata.
In secondary analyses, we restricted the sample to the immigrant group to assess the impact of the differing classifications of small and large for gestational age on the risk of adverse neonatal and obstetric outcomes. We further controlled for several immigration-related characteristics from the immigration database that were last updated at the time of arrival to Canada, including marital status, maternal education, knowledge of English or French, refugee status and years of residence in Canada. To evaluate whether each adverse outcome among infants classified as small or large for gestational age was more accurately identified with the world

Table 1: Maternal characteristics of singleton live births in nonimmigrant and immigrant groups

\begin{tabular}{|c|c|c|c|c|c|c|c|c|}
\hline \multirow[b]{2}{*}{ Characteristic } & \multirow[b]{2}{*}{$\begin{array}{c}\text { Nonimmigrants, } \\
\text { no. }(\%) \text { of births* } \\
n=761260\end{array}$} & \multicolumn{7}{|c|}{ Immigrants, by world region; no. (\%) of births* } \\
\hline & & $\begin{array}{c}\text { All immigrants } \\
n=328387\end{array}$ & $\begin{array}{c}\text { Europe, } \\
\text { Western } \\
\text { nations } \\
n=51268\end{array}$ & $\begin{array}{c}\text { Africa, } \\
\text { Caribbean } \\
n=42813\end{array}$ & $\begin{array}{c}\text { North Africa, } \\
\text { Middle East } \\
n=32920\end{array}$ & $\begin{array}{c}\text { Latin } \\
\text { America } \\
n=25255\end{array}$ & $\begin{array}{c}\text { East Asia, } \\
\text { Southeast } \\
\text { Asia, Pacific } \\
n=73979\end{array}$ & $\begin{array}{l}\text { South Asia } \\
n=102152\end{array}$ \\
\hline \multicolumn{9}{|l|}{ Age group, yr } \\
\hline $35-49$ & $139405(18.3)$ & $75478(23.0)$ & $12721(24.8)$ & $10973(25.6)$ & 7555 (22.9) & $5751(22.8)$ & $24092(32.6)$ & $14386(14.1)$ \\
\hline \multicolumn{9}{|l|}{ Parity } \\
\hline 0 & $354345(46.5)$ & $140036(42.6)$ & $23940(46.7)$ & $14942(34.9)$ & $12661(38.5)$ & $10810(42.8)$ & $36021(48.7)$ & $41662(40.8)$ \\
\hline 1 & $365664(48.0)$ & $166235(50.6)$ & $25045(48.9)$ & $21020(49.1)$ & $16646(50.6)$ & $12709(50.3)$ & $36283(49.0)$ & $54532(53.4)$ \\
\hline 2 & $143158(18.8)$ & 75359 (22.9) & $9645(18.8)$ & $8838(20.6)$ & $6410(19.5)$ & $6105(24.2)$ & $18870(25.5)$ & $25491(25.0)$ \\
\hline 3 & $158762(20.9)$ & $62244(19.0)$ & $10259(20.0)$ & $6566(15.3)$ & $5846(17.8)$ & 4957 (19.6) & 14468 (19.6) & 20148 (19.7) \\
\hline 4 & $174292(22.9)$ & 50525 (15.4) & $11707(22.8)$ & $4421(10.3)$ & $5841(17.7)$ & 3913 (15.5) & $11748(15.9)$ & 12895 (12.6) \\
\hline 5 (highest) & $145225(19.1)$ & $29451 \quad(9.0)$ & 9156 (17.9) & 2340 & $3430(10.4)$ & $2425 \quad(9.6)$ & $6957 \quad(9.4)$ & $5143 \quad(5.0)$ \\
\hline Unknown & $6065 \quad(0.8)$ & 1089 & $204 \quad(0.4)$ & $161 \quad(0.4)$ & $127 \quad(0.4)$ & $98 \quad(0.4)$ & $302 \quad(0.4)$ & $197 \quad(0.2)$ \\
\hline Not married $\dagger$ & - & $133435(40.6)$ & 24130 (47.1) & $26675(62.3)$ & $10377(31.5)$ & $13610(53.9)$ & 30759 (41.6) & $27884(27.3)$ \\
\hline \multicolumn{9}{|l|}{ Educationt } \\
\hline $\begin{array}{l}\text { Less than high } \\
\text { school }\end{array}$ & - & $122799(37.4)$ & 19257 (37.6) & $24045(56.2)$ & 11149 (33.9) & $13551(53.7)$ & $22252(30.1)$ & 32545 (31.9) \\
\hline $\begin{array}{l}\text { High school } \\
\text { or some } \\
\text { postsecondary }\end{array}$ & - & $107291(32.7)$ & 17012 (33.2) & 15266 (35.7) & $11127(33.8)$ & 7217 (28.6) & 26091 (35.3) & 30578 (29.9) \\
\hline $\begin{array}{l}\text { Duration of } \\
\text { residence in } \\
\text { Canada, yr, } \\
\text { mean } \pm \text { SD }\end{array}$ & - & $7.1 \pm 5.9$ & $8.2 \pm 6.5$ & $8.4 \pm 6.1$ & $5.7 \pm 5.4$ & $8.4 \pm 6.6$ & $6.0 \pm 5.4$ & $5.0 \pm 4.5$ \\
\hline $\begin{array}{l}\text { Note: SD = standar } \\
\text { *Unless specified o } \\
\text { †At time of arrival }\end{array}$ & $\begin{array}{l}\text { viation. } \\
\text { wise. } \\
\text { anada. }\end{array}$ & & & & & & & \\
\hline
\end{tabular}


region-specific birth-weight curves than with the Canadian curve, we computed the sensitivity and specificity for each outcome and used a nonparametric approach to test for differences in the areas under the curve of the generated receiver operating characteristics curve..$^{23}$

All analyses were conducted with the use of SAS software (version 9.3; SAS Institute).

\section{Ethics approval}

The study protocol was approved by the St. Michael's Hospital Research Ethics Board (protocol no. 12-087).

\section{Results}

Of 1284461 eligible singleton infants, we excluded 8856 births for at least 1 of the following reasons: missing or invalid data on infant sex ( $n=69)$; missing data on birth weight $(n=34)$ or birth weight below $250 \mathrm{~g}(n=122)$; missing data on gestational age $(n=246)$ or gestational age not in study range ( $n=1118)$; unknown parity $(n=401)$; maternal country of origin unknown among immigrants $(n=98)$; or infants of women not linked to the immigration database and whose first date of eligibility for the provincial health coverage began after December 2010, when the immigration database ended $(n=7147)$. Of the 1275605 records with complete data, we excluded a further 185785 births to women without a matching immigration record whose first eligibility date for provincial health insurance coverage was after April 1991 (when a new health card numbering system was implemented), because we could not tell who were immigrants and who were Canadian-born women in this group of newcomers to Ontario. Finally, because of the small number, we excluded 153 infants in the immigrant group who were classified as small for gestational age by the world region-specific birth-weight curves but not by the Canadian curve, most of whom were very preterm infants, as well as 20 infants who were classified as large

Table 2: Neonatal characteristics of singleton live births in nonimmigrant and immigrant groups

\begin{tabular}{|c|c|c|c|c|c|c|c|c|}
\hline Characteristic & $\begin{array}{c}\text { Nonimmigrants, } \\
\text { no. }(\%) \text { of births* } \\
n=761260\end{array}$ & $\begin{array}{c}\text { All } \\
\text { immigrants } \\
n=328387\end{array}$ & $\begin{array}{c}\text { Europe, } \\
\text { Western } \\
\text { Nations } \\
n=51268\end{array}$ & $\begin{array}{c}\text { Africa, } \\
\text { Caribbean } \\
n=42813\end{array}$ & $\begin{array}{c}\text { North Africa, } \\
\text { Middle East } \\
n=32920\end{array}$ & $\begin{array}{c}\text { Latin } \\
\text { America } \\
n=25255\end{array}$ & $\begin{array}{c}\text { East Asia, } \\
\text { Southeast } \\
\text { Asia, Pacific } \\
n=73979\end{array}$ & $\begin{array}{l}\text { South Asia } \\
n=102152\end{array}$ \\
\hline \multicolumn{9}{|l|}{ Small for gestational age } \\
\hline $\begin{array}{l}\text { Based on world region- } \\
\text { specific birth-weight } \\
\text { curves }\end{array}$ & $82257(10.8)$ & $33780(10.3)$ & $5265(10.3)$ & $4609(10.8)$ & 3273 (9.9) & $2721(10.8)$ & $7468(10.1)$ & $10444(10.2)$ \\
\hline $\begin{array}{l}\text { Based only on Canadian } \\
\text { curve }\end{array}$ & $0 \quad(0.0)$ & $20431 \quad(6.2)$ & $128 \quad(0.2)$ & $2594 \quad(6.1)$ & 1089 & 1153 & $4415 \quad(6.0)$ & $11052(10.8)$ \\
\hline \multicolumn{9}{|l|}{ Large for gestational age } \\
\hline $\begin{array}{l}\text { Based only on world } \\
\text { region-specific curves }\end{array}$ & $0 \quad(0.0)$ & 14282 & $602(1.2)$ & $1445(3.4)$ & $1334 \quad(4.1)$ & $853 \quad(3.4)$ & $4174 \quad(5.6)$ & $5874 \quad(5.8)$ \\
\hline Male sex & 389967 (51.2) & $168885(51.4)$ & $26371(51.4)$ & $21710(50.7)$ & $16828(51.1)$ & $13072(51.8)$ & $38226(51.7)$ & $52678(51.6)$ \\
\hline $\begin{array}{l}\text { Preterm birth } \\
(23-36 \mathrm{wk})\end{array}$ & $48366 \quad(6.4)$ & 19110 & $2608 \quad(5.1)$ & 3108 (7.3) & $1584 \quad(4.8)$ & 1665 (6.6) & 4189 (5.7) & $5956 \quad(5.8)$ \\
\hline $\begin{array}{l}\text { Very preterm birth } \\
(23-31 \mathrm{wk})\end{array}$ & $5887 \quad(0.8)$ & $2648 \quad(0.8)$ & $330 \quad(0.6)$ & $643 \quad(1.5)$ & $194(0.6)$ & $239(0.9)$ & $516 \quad(0.7)$ & $726 \quad(0.7)$ \\
\hline \multicolumn{9}{|l|}{ Birth weight, g } \\
\hline Median (IQR) & $\begin{array}{c}3452 \\
\text { (3 } 122-3785)\end{array}$ & $\begin{array}{c}3311 \\
\text { (3 004-3 627) }\end{array}$ & $\begin{array}{c}3460 \\
\text { (3 144-3 778) }\end{array}$ & $\begin{array}{c}3320 \\
(3000-3653)\end{array}$ & $\begin{array}{c}3380 \\
(3080-3682)\end{array}$ & $\begin{array}{c}3336 \\
(3015-3660)\end{array}$ & $\begin{array}{c}3275 \\
(2992-3570)\end{array}$ & $\begin{array}{c}3235 \\
\text { (2 934-3 544) }\end{array}$ \\
\hline
\end{tabular}


for gestational age by the Canadian curve but not by the world region-specific curves. This left 1089647 live births (328 387 to immigrants and 761260 to nonimmigrants) for the main analysis.

In the immigrant group, more than half of births were to East and South Asian women (53.6\%). Most maternal characteristics varied according to maternal world region (Table 1). Notably, women from Africa and the Caribbean had the highest parity and were more strongly concentrated in poor neighbourhoods compared with women in the other immigrant groups, who themselves were more likely to reside in lowincome areas than nonimmigrant women.

In the immigrant group, $33780(10.3 \%)$ of the infants were classified as small for gestational age on both the Canadian and the world region-specific birth-weight curves; 20431 (6.2\%) were classified as small for gestational age on the Canadian curve but not on the world region-specific curves, 15467 (75.7\%) of whom had mothers from South and East Asia (Table 2). A total of 17684 (5.4\%) of the newborns in the immigrant group were classified as large for gestational age on both the Canadian and world region curves, and 14282 (4.3\%) were classified as large for gestational age on the world region curves but not on the Canadian curve. Infants of immigrant women were smaller overall than those of nonimmigrant women, and the differences varied substantially according to maternal birthplace: infants of European women had birth weights similar to those of infants of nonimmigrant women, whereas infants of East or South Asian women had the lowest birth weights.
Differences in the odds of adverse outcomes were seen between infants of immigrant and nonimmigrant women when the Canadian and world region-specific cut-off points for small for gestational age were used (Table 3 ). When defined by the Canadian curve, small-forgestational-age infants of immigrant women were at lower odds of neonatal death than those of nonimmigrant women (adjusted OR 0.83, 95\% CI 0.72-0.95). The opposite was observed when the world region-specific curves were used, with small-for-gestational-age infants of immigrant women being at higher odds of neonatal death than those of nonimmigrant women (adjusted OR 1.24, 95\% CI 1.08-1.42), particularly for term infants (adjusted OR 1.56, 95\% CI 1.13-2.15) (Table 3). Similarly, when defined by the Canadian curve, small-for-gestational-age newborns of immigrant women were at lower odds of prolonged hospital stay, mechanical ventilation and intrauterine hypoxia or birth asphyxia than infants of nonimmigrant women; however, the differences disappeared or reversed direction when the world region-specific curves were used, except for intrauterine hypoxia or birth asphyxia (Table 3).

For many adverse neonatal and obstetric outcomes associated with being large for gestational age, the aforementioned pattern was reversed: when defined as large for gestational age by the Canadian curve, infants of immigrant women and nonimmigrant women did not differ in odds of prolonged hospital stay, mechanical ventilation, birth trauma or shoulder dystocia, but when

Table 3: Adverse neonatal outcomes among small-for-gestational-age (SGA) infants in nonimmigrant and immigrant groups according to whether weight classification was defined by Canadian birth-weight curve or by world region-specific birth-weight curves

\begin{tabular}{|c|c|c|c|c|c|c|c|}
\hline Outcome & \multicolumn{4}{|c|}{ SGA according to Canadian curve } & \multicolumn{3}{|c|}{ SGA according to world region-specific curves } \\
\hline \multicolumn{8}{|l|}{ Neonatal death } \\
\hline $\begin{array}{l}\text { Preterm infants } \\
(23-36 \mathrm{wk})\end{array}$ & $551(67.8)$ & $286(63.9)$ & $0.94(0.81-1.09)$ & $0.93(0.80-1.09)$ & 278 (77.8) & $1.16(1.00-1.35)$ & $1.15(0.99-1.35)$ \\
\hline $\begin{array}{l}\text { Term infants } \\
\text { (37-41 wk) }\end{array}$ & $102 \quad(1.4)$ & $80 \quad(1.6)$ & $1.17(0.87-1.57)$ & $1.18(0.87-1.59)$ & $65 \quad(2.2)$ & $1.57(1.15-2.14)$ & $1.56(1.13-2.15)$ \\
\hline Hospital stay $\geq 7 \mathrm{~d}$ & $6762 \quad(82.2)$ & $3922(72.3)$ & $0.87(0.83-0.91)$ & $0.84(0.80-0.87)$ & 3239 (97.4) & $1.18(1.13-1.24)$ & $1.13(1.08-1.18)$ \\
\hline
\end{tabular}


defined as large for gestational age by world region-specific curves, infants of immigrant women were at lower odds of these outcomes than infants of nonimmigrant women (Table 4). When defined by either curve, large-for-gestational-age infants of immigrant women were associated with higher odds of admission to a neonatal intensive care unit and third- or fourth-degree perineal lacer- ation, and lower odds of portpartum hemorrhage, than infants of nonimmigrant women.

Among small-for-gestational-age infants, those born to immigrant women from Europe, North Africa/Middle East and Latin America had a risk of neonatal death similar to that of infants of nonimmigrant women, irrespective of whether the Canadian or world region-specific curves were

Table 4: Adverse neonatal and obstetric outcomes among large-for-gestational-age (LGA) infants in nonimmigrant and immigrant groups according to whether weight classification was defined by the Canadian birth-weight curve or by world region-specific birth-weight curves

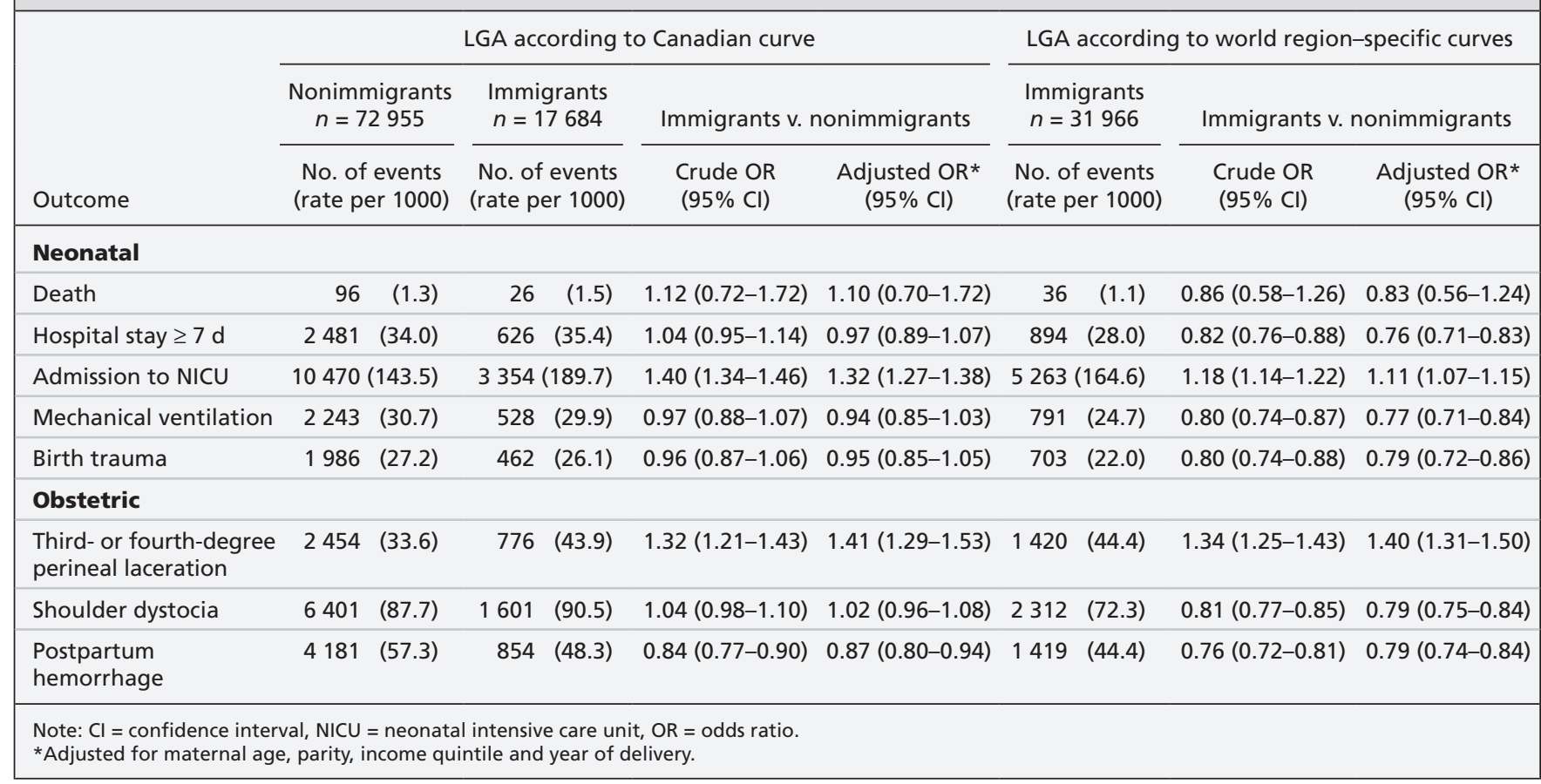

Table 5: Adjusted risk of neonatal death among small-for-gestational-age (SGA) and non-SGA infants according to whether weight classification was defined by the Canadian birth-weight curve or by world region-specific birth-weight curves

\begin{tabular}{|c|c|c|c|c|c|}
\hline \multirow{2}{*}{ Group } & \multicolumn{5}{|c|}{ Group; adjusted OR* $(95 \% \mathrm{Cl})$} \\
\hline & All infants & \multicolumn{2}{|c|}{ SGA infants } & \multicolumn{2}{|c|}{ Non-SGA infants } \\
\hline Nonimmigrants (referent) & 1.00 & 1.00 & 1.00 & 1.00 & 1.00 \\
\hline \multicolumn{6}{|l|}{$\begin{array}{l}\text { Immigrants by world region } \\
\text { of origin }\end{array}$} \\
\hline Europe, Western nations & $1.04(0.82-1.30)$ & $1.24(0.94-1.64)$ & $1.27(0.96-1.68)$ & $0.82(0.55-1.21)$ & $0.82(0.55-1.21)$ \\
\hline Africa, Caribbean & $1.62(1.32-1.97)$ & $1.48(1.18-1.85)$ & $2.25(1.79-2.83)$ & $0.79(0.51-1.23)$ & $0.84(0.55-1.27)$ \\
\hline North Africa, Middle East & $1.01(0.76-1.33)$ & $0.84(0.58-1.21)$ & $1.08(0.74-1.57)$ & $1.02(0.66-1.59)$ & $1.03(0.67-1.59)$ \\
\hline Latin America & $1.04(0.76-1.43)$ & $0.91(0.63-1.32)$ & $1.30(0.89-1.89)$ & $0.78(0.44-1.39)$ & $0.74(0.42-1.31)$ \\
\hline
\end{tabular}


used (Table 5). However, small-for-gestationalage infants of immigrant women of East Asian, Southeast Asian and Pacific origin (adjusted OR $0.65,95 \%$ CI $0.50-0.84$ ) and of South Asian origin (adjusted OR $0.57,95 \%$ CI $0.46-0.71$ ) were at lower risk of neonatal death than small-forgestational-age infants of nonimmigrant women when their size was defined by the Canadian curve, but not when defined by the world regionspecific curves (Table 5). In contrast, small-forgestational-age infants of women of African and Caribbean origin were at higher risk of neonatal death than those of nonimmigrant women, according to both the Canadian curve (adjusted OR 1.48, 95\% CI 1.18-1.85) and the world region-specific curve (adjusted OR 2.25, 95\% CI 1.79-2.83).

Secondary analyses restricted to immigrants showed that infants classified as small for gestational age on both curves were at much higher risk of neonatal death (adjusted OR 14.74, 95\% CI 12.32-17.64) and other adverse outcomes than infants who were not small for gestational age (Appendices 3 and 4, available at www.cmaj.ca /lookup/suppl/doi:10.1503/cmaj.140748/-/DC1); those classified as small for gestational age only by the Canadian curve were at minimally or no higher risk. Compared with infants who were not large for gestational age, those classified as large for gestational age on both curves were at higher risk for all outcomes except neonatal death (Appendices 5-7, available at www.cmaj.ca/lookup/suppl /doi:10.1503/cmaj.140748/-/DC1). Even when large for gestational age was defined by the world region-specific curve alone, the risk remained higher for maternal or newborn trauma and obstetric outcomes (Appendices 5-7).

World region-specific curves had higher specificity and lower sensitivity than the Canadian curve for small for gestational age, which resulted in higher area-under-the-curve values for most outcomes, but the differences were relatively small (Appendix 8, available at www.cmaj.ca /lookup/suppl/doi:10.1503/cmaj.140748/-/DC1).

\section{Interpretation}

By applying a birth-weight curve developed for the Canadian-born population to infants of immigrant women, we found that $16.5 \%$ met the definition of small for gestational age and 5.4\% were considered large for gestational age, instead of the theoretical $10 \%$, which was achieved when the world region-specific curves were used. The rates differed because the birth-weight distribution of most immigrant groups is shifted toward lower birth-weight values. Small-for-gestational-age newborns of immigrant women were at lower risk of neonatal death and other adverse outcomes than infants of nonimmigrant women when the Canadian curve was used, but the differences disappeared or reversed direction when the world region-specific curves were used. This finding suggests that the additional newborns classified as small for gestational age by the Canadian curve but not by the world region-specific curves were not at substantially increased risk of neonatal death or other adverse outcomes. Many of these infants may be at risk of undergoing unwarranted testing and interventions if clinical decisions rely solely on the use of the Canadian birth-weight curve. Likewise, world region-specific curves better identify newborns associated with an increased risk of delivery-related trauma, perineal laceration, obstructed labour due to shoulder dystocia and postpartum hemorrhage. World region-specific curves are more informative for infants of immigrant women from places where the birth-weight distribution is markedly different from that of the Canadian-born population, such as East and South Asia, but not for infants of immigrants from Europe, where the birth-weight distribution resembles that of Canada's.

Our findings are consistent with those of studies involving infants born to women from East and South Asia in British Columbia ${ }^{24}$ and Washington State ${ }^{25}$ and to low-risk African-American women. ${ }^{26}$ The studies showed that, despite their higher rates of small-for-gestational-age infants based on a single standard, these infants did not have a higher risk of adverse outcomes. Whereas previous studies assessed the impact of maternal birthplace or ethnicity on small for gestational age, ${ }^{24-26}$ we simultaneously evaluated the impact of maternal origin on large for gestational age and on a wide array of outcomes including neonatal death, thus generating a more complete picture.

Infants of immigrant women classified as large for gestational age by the world regionspecific curves and not the Canadian curve were also at significantly higher risk of neonatal and obstetric outcomes, including birth trauma, perineal laceration, obstructed labour due to shoulder dystocia and postpartum hemorrhage, findings that are consistent with those from previous studies using customized standards. ${ }^{15-17}$ Although the customized standards included ethnicity or birthplace, among other individual characteristics, the independent contribution of maternal geographic origin was not reported in those studies. Mikolajczyk and colleagues ${ }^{18}$ showed that individually customized standards did not improve the discrimination of adverse perinatal outcomes beyond using a fetal growth standard solely based on maternal country of birth, which suggests that maternal birthplace is a sufficient characteristic for customization of birth-weight curves. 


\section{Limitations}

The birth-weight curves we used were based on a cross-section of the entire population of singleton live births in Ontario, including healthy and unhealthy newborns. ${ }^{4}$ Weight for gestational age was assessed at birth, and therefore these references may not necessarily reflect normal fetal growth patterns. ${ }^{27}$ Because the curves categorized newborns by maternal world region of origin, they cannot fully account for betweencountry and ethnic differences within each region. Although we adjusted for several characteristics of immigrant mothers, our findings may be affected by residual confounding from the unaccounted contribution of mode of delivery and parental characteristics, such as individual-level socioeconomic status, paternal world region of origin, parental height, maternal weight before pregnancy, and nutrition and health behaviours such as smoking. We tailored the birth-weight curves to immigrants to Ontario, ${ }^{4}$ whose distribution by world region is representative of immigrants to $\mathrm{Canada}^{28}$ but not necessarily of immigrants in other countries. Our findings relate to maternal birthplace, not maternal ethnicity, and therefore may not apply to newborns of second-generation South Asian women, for example, who themselves were born in an industrialized country. Finally, we could not include fetal death as a study outcome because of the lack of information on stillbirths' birth weights.

\section{Conclusion}

World region-specific birth-weight curves seemed to be more appropriate than a single $\mathrm{Ca}$ nadian population-based curve for assessing the risk of adverse neonatal and obstetric outcomes among small- and large-for-gestational-age infants born to immigrant women. This was especially evident among infants whose mothers were from world regions where the birth-weight distribution differed markedly from that of the Canadian-born population, such as East and South Asian immigrants, who accounted for more than half of the births to immigrants in the study. Because small or large size for gestational age is determined at birth - the same time as some adverse outcomes occur — prevention of some related outcomes remains a challenge. Clinicians who care for pregnant women and newborns in immigrant groups may find world region-specific birth-weight curves helpful to refine clinical decision-making, especially to prevent events that occur after birth, such as infant death or morbidity, or hospital readmission.

Estimating the number of newborns who may be spared unnecessary prolonged stay in hospi- tal, special care, or referral for specialized pediatric or nutritional interventions, and the cost savings therein, is a worthwhile step in evaluating the impact of applying world region-specific curves in certain immigrant populations.

\section{References}

1. Low birthweight: country, regional and global estimates. New York: UNICEF, World Health Organization; 2004.

2. Neonatal and perinatal mortality. Country, regional and global estimates. Geneva: United Nations Children's Fund, World Health Organization; 2006.

3. Sobotka T. Overview chapter 7: the rising importance of migrants for childbearing in Europe. Demogr Res 2008;19(article 9):225-248.

4. Ray JG, Sgro M, Mamdani MM, et al. Birth weight curves tailored to maternal world region. J Obstet Gynaecol Can 2012:34:159-71.

5. Seaton SE, Yadav KD, Field DJ, et al. Birthweight centile charts for South Asian infants born in the UK. Neonatology 2011;100: 398-403.

6. Singer LT, Salvator A, Guo S, et al. Maternal psychological distress and parenting stress after the birth of a very low-birthweight infant. JAMA 1999;281:799-805.

7. Cha HH, Kim JY, Choi SJ, et al. Can a customized standard for large for gestational age identify women at risk of operative delivery and shoulder dystocia? J Perinat Med 2012;40:483-8.

8. Larkin JC, Speer PD, Simhan HN. A customized standard of large size for gestational age to predict intrapartum morbidity. Am J Obstet Gynecol 2011;204:499.e1-10.

9. Pasupathy D, McCowan LM, Poston L, et al. Perinatal outcomes in large infants using customised birthweight centiles and conventional measures of high birthweight. Paediatr Perinat Epidemiol 2012;26:543-52.

10. Boulet SL, Alexander GR, Salihu HM, et al. Macrosomic births in the United States: determinants, outcomes, and proposed grades of risk. Am J Obstet Gynecol 2003;188:1372-8.

11. Melamed N, Gavish O, Eisner M, et al. Third- and fourth-degree perineal tears - incidence and risk factors. J Matern Fetal Neonatal Med 2013;26:660-4.

12. Weissmann-Brenner A, Simchen MJ, Zilberberg E, et al. Maternal and neonatal outcomes of large for gestational age pregnancies. Acta Obstet Gynecol Scand 2012;91:844-9.

13. Clausson B, Gardosi J, Francis A, et al. Perinatal outcome in SGA births defined by customised versus population-based birthweight standards. BJOG 2001;108:830-4.

14. Figueras F, Figueras J, Meler E, et al. Customised birthweight standards accurately predict perinatal morbidity. Arch Dis Child Fetal Neonatal Ed 2007;92:F277-80.

15. Hutcheon JA, Zhang X, Cnattingius S, et al. Customised birthweight percentiles: Does adjusting for maternal characteristics matter? BJOG 2008;115:1397-404.

16. Hutcheon J. Do customized birth weight charts add anything but complexity to the assessment of fetal growth? J Obstet Gynaecol Can 2014;36:107-13.

17. Zhang X, Platt RW, Cnattingius S, et al. The use of customised versus population-based birthweight standards in predicting perinatal mortality. BJOG 2007;114:474-7.

18. Mikolajczyk RT, Zhang J, Betran AP, et al. A global reference for fetal-weight and birthweight percentiles. Lancet 2011;377:1855-61.

19. Urquia ML, Frank JW, Moineddin R, et al. Immigrants' duration of residence and adverse birth outcomes: a populationbased study. BJOG 2010;117:591-601

20. Urquia ML, Frank JW, Moineddin R, et al. Does time since immigration modify neighborhood deprivation gradients in preterm birth? A multilevel analysis. J Urban Health 2011;88:959-76.

21. Birthweight curves for newborns according to maternal ancestry. Toronto: St. Michael's Hospital. Available: www.stmichaels hospital.com/birthweights.php (accessed 2014 Nov. 3).

22. 2006 census dictionary. Ottawa: Statistics Canada; 2010. Catalogue no. 92-566-X

23. DeLong ER, DeLong DM, Clarke-Pearson DL. Comparing the areas under two or more correlated receiver operating characteristic curves: a nonparametric approach. Biometrics 1988;44:837-45.

24. Kierans WJ, Joseph KS, Luo ZC, et al. Does one size fit all? The case for ethnic-specific standards of fetal growth. BMC Pregnancy Childbirth 2008;8:1.

25. Hanley GE, Janssen PA. Ethnicity-specific birthweight distributions improve identification of term newborns at risk for shortterm morbidity. Am J Obstet Gynecol 2013;209:428.e1-6.

26. Alexander GR, Kogan MD, Himes JH, et al. Racial differences in birthweight for gestational age and infant mortality in 
extremely-low-risk US populations. Paediatr Perinat Epidemiol 1999;13:205-17.

27. Zhang J, Merialdi M, Platt LD, et al. Defining normal and abnormal fetal growth: promises and challenges. Am J Obstet Gynecol 2010;202:522-8.

28. Facts and figures 2011 - immigration overview: permanent and temporary residents. Ottawa: Research and Evaluation Branch, Citizenship and Immigration Canada; 2012. Available: www.cic .gc.ca/english/resources/statistics/facts2011/index.asp (accessed 2014 Oct. 29)

Affiliations: Centre for Research on Inner City Health (Urquia), Li Ka Shing Knowledge Institute, St. Michael's Hospital; Department of Medicine (Berger, Ray), St. Michael's Hospital; Institute for Clinical Evaluative Sciences (Urquia, Ray), Dalla Lana School of Public Health (Urquia), Faculty of Medicine (Berger, Ray), University of Toronto, Toronto, Ont.

Contributors: Marcelo Urquia conceived the study, conducted the analyses and drafted the first version of the manuscript. Marcelo Urquia, Howard Berger and Joel Ray contributed to the study design, interpretation of the results and writing of the manuscript. All of the authors approved the final version submitted for publication and agreed to act as guarantors of the work.
Funding: The study was funded by a grant from the Canadian Institutes of Health Research (CIHR grant no. MOP123267). Marcelo Urquia holds a CIHR New Investigator Award. Joel Ray holds a CIHR Chair in Reproductive and Child Health Services and Policy Research.

Acknowledgement: The study was possible thanks to the Institute for Clinical Evaluative Sciences (ICES), which is supported by an annual grant from the Ontario Ministry of Health and Long-Term Care. The opinions, results and conclusions reported in this article are those of the authors and are independent from the funding sources. No endorsement by ICES or the Ontario Ministry of Health and Long-Term Care is intended or should be inferred.

Members of the Canadian Curves Consortium: Kathlyn Babaran-Henfrey, Howard Berger, Saleha Bismilla, Alan Bocking, Marilyn Booth (cochair), Douglas Campbell, Maria Chiu, Lisa Colizza, Margaret de Groh, Leanne De Souza, Richard Glazier, Astrid Guttmann, Manavi Handa, Robert Hilliard, Christopher Longo, Jonathon Maguire, Patricia Mousmanis, Alison Park, Henry Roukema, Joel G. Ray (cochair), Jennifer Roy, Michael Sgro, Graeme N. Smith, Karen Tu, Pat Vanderkooy, Marcelo Urquia, William Watson and Nancy Watts 